\title{
A Study on Risk Taking Behaviour among Adolescents and Their Attachment with Parents and Peers
}

\author{
Uzaina $^{1 *}$, Dr. Anupama Srivastava ${ }^{2}$
}

\section{ABSTRACT}

The present study examined the role of attachment level of adolescents with parents and peers and their indulgence in risk taking behaviour. Several studies have been reviewed on parental relationship with adolescents and adolescents risk taking behaviour. Researches over last few years have shown that indulgence of adolescents in risk taking behaviour and sexual activities is due to poor parenting practices and one of the prevailing factors is peer attachment. Since no studies related to attachment level of adolescents with parents and indulgence of adolescents in risk taking behaviour have been reviewed in Indian context. Thus to see the status of parent and peer attachment and risk taking behaviour among adolescents, this study was done on a sample of 100 undergraduate students that comprise of 50 males and 50 females. The results showed that females were more attached with their parents and peers in comparison to males. Risk taking behaviour and sexual activities were found to be higher among males than females. It was found that in females the desire of indulging in substance use and sexual activity was low as compared to males. First time indulgence in such behaviour was reported in presence of peers and due to peer pressure. Males reported that they faced ridicule because of not engaging in sexual activities and substance use. Thus positive peer pressure was found helpful in keeping females away from risk taking behaviour.

Keywords: Adolescents, Risk taking behaviour, Peer Pressure, Sexual Debut among Adolescents.

Adolescence is a time of many changes, some of which are subtle and some are apparent. Several changes take place simultaneously during the adolescence phase, some impacting there thinking, emotions and behaviour more than others. No aspect of adolescent development has received more attention from public and researcher than parent adolescent relationship. Much of the research indicated that despite altered pattern of interaction, relationship with parent remain important social and emotional resources well beyond the childhood years. Yet it is a challenge

\footnotetext{
${ }^{1}$ Doctoral Fellow, Department of Psychology, Aligarh Muslim University, India

${ }^{2}$ Associate Professor, Amity University Manesar, India

*Responding Author

(C) 2016 I Uzaina, A Srivastava; licensee IJIP. This is an Open Access Research distributed under the terms of the Creative Commons Attribution License (http://creativecommons.org/licenses/by/2.0), which permits unrestricted use, distribution, and reproduction in any Medium, provided the original work is properly cited.
} 
to reconcile this conclusion with the widespread perception that parent - adolescent relationships decline in quality and influence over the course of the adolescent years. In general, it may be observed that the adolescence period has been and continues to be considered a different time of life for main these reasons:

1) There is little opportunity to participate in an inherently meaningful activity, as the culture of the young is riddled with hypocrisy, groupism and short - term goals.

2) The school setting in which they spend most of their waking hours tends to reinforce artificial rules of acceptance and over reliance and on conformity.

Adolescence is a time of transformation in many areas of an individual's life. In the midst of these rapid physical, emotional, and social changes, youth begin to question adult standards and the need for parental guidance. For many youth, adolescence marks the onset of sexual activity and experimentation. Adolescent also starts indulging in substance use because of clusters of problems and risk taking behaviour. Predisposing factors include temperament, genetics, parenting and peer behaviour. It has been seen through various studies that due to these physical, psychological and behavioural changes in the adolescent state of conflict arise due to parental pressure and peer pressure. Because the adolescents start making new relations and they start spending more time with peers, due to which parents start restricting them which makes adolescents rebellious.

According to Bowlby's model (1973), the child with secure attachment to principal care-givers carries an unconscious assurance that $\mathrm{s} /$ he has access to trustworthy, helpful others, and views $\mathrm{him} /$ herself as worthy of love and caring. Such a child is more likely to develop a balance of selfreliance and appropriate help-seeking capacities as s/he matures. As might be expected from the preceding theory, there is evidence of a strong link between the adolescent's intimate relationships and such outcomes as self-concept, psychological adjustment, and physical health. Burke and Weir (1978) in their study of 13- to 20-year-olds found that those adolescents expressing greater satisfaction with help received from peers, and particularly from parents, experienced greater psychological well-being. Rosenberg (1965) reported a stable relationship throughout adolescence between self-esteem and perception of warm relationships with parents.

During adolescence, peer group plays a very important role in their lives and typically replace family as the center of social and leisure activities. These results into many risk taking activities such as smoking, aggressive behaviour or indulging into sexual activities due to peer pressure. How peer promotes way for risk taking behaviour such as sexual activity, smoking etc. Relationship with parent and peer is very important, it is supportive and sometimes parents start expecting too much due to which conflict arises between them. Cohen, Richardson, and LaBree'(1994) in a study found that reported levels of positive feedback, encouragement, and physical affection from parents predicted a lower risk of alcohol and cigarette use. 
The researches over last few years shows that indulgence of adolescents in risk taking behaviour and sexual activities is due to poor parenting practices and one of the prevailing factor is peer attachment. Adolescents during this age want to make identity in peer group and thus gets involve in all these activities.

\section{Purpose:}

1. To assess the attachment level of adolescents with parents and peer.

2. To study the risk taking behaviour among adolescents.

\section{METHOD}

\section{Sample:}

The sample of the present study comprised of 50 males and 50 females. They belong to age range of 18 to 21 years and were undergraduate students.

\section{Assumptions:}

1) There will be significant gender difference in attachment level with mother.

2) There will be significant gender difference in attachment level with father.

3) There will be significant gender difference among adolescents with respect to their attachment level with peers.

4) There will be significant gender difference among adolescents' risk taking behaviour.

\section{Tools and administration:}

In the present study two tools were used, the description and scoring of the tools is being given here-

A) Inventory of Parent and Peer Attachment by Gay. C. Armsden and Mark T. Greenberg (1987. The IIPA consists of three 25 - item instruments that measure one's attachment to parents and peers. Scoring- all three instruments are scored independently.

B) An interview questionnaire for measuring risk taking behaviour in adolescent was constructed by the researcher. It comprised of two factors for measuring risk taking behaviour i.e. substance use and sexual debut.

- $\quad$ The first part of interview consists of two aspects - a) questions for those who have tried substance. b) Questions for those who have never tried any substance.

- $\quad$ The second part of interview also consisted of two aspects- a) for those who have engaged in sexual activity. b) For those who have not engaged in sexual activity.

\section{INTERPRETATION AND DISCUSSION OF THE RESULT}

The purpose of the study was to measure the role of parent and peer attachment in adolescents' risk taking behaviour. Below are the tables showing attachment level among female and male adolescents, the $t$ value is also given to see the level of significance between the attachment levels of both the groups. 
1 (a) Attachment with mother- was measured using Inventory of Parent and Peer Attachment by Gay. C. Armsden and Mark T. Greenberg. Below is the table showing mean scores and $t$ value of adolescents' on attachment with mother subscale:

\begin{tabular}{|c|c|c|c|}
\hline Males & Females & $\mathbf{T}$ & Level of significance \\
\hline 90.9 & 94.2 & 0.02 & $<.05$ \\
\hline
\end{tabular}

Table 1.1 Showing the mean difference and $t$ value of males and females on attachment with mother

The mean score of Males and Females in attachment with mother is 90.9 and 94.2 respectively. The $t$ value is 0.02 . The obtained difference between the mean scores of Males and Females with respect to their attachment level with mother is 'insignificant' at 0.05 Level. It can be seen from the mean values that, females have a higher mean value, which means females were more attached with their mothers as compared to males.

1 (b) Attachment with father- was measured using Inventory of Parent and Peer Attachment by Gay. C. Armsden and Mark T. Greenberg. Below is the table showing mean scores and $t$ value of adolescents' on attachment with father subscale:

\begin{tabular}{|l|l|l|l|}
\hline Males & Females & T & Level of significance \\
\hline 79.3 & 99.1 & $2.4^{*}$ & $>.05$ \\
\hline
\end{tabular}

Table 1.2: showing the mean difference and $t$ value of males and females on attachment with father.

The mean score of Males and Females on attachment with father was 79.3 and 99.1 respectively. The $t$ value is 2.4, which shows that the obtained difference between mean score of males and females with respect to their attachment level with father 'is significant' at 0.05 Level. This finding is supported by Kenny and Donaldson (1991)who in a study found that women were more attached to their parents and felt that parents had a more significant role in emotional support in their lives.

1 (c) Attachment with peers- was measured using Inventory of Parent and Peer Attachment by Gay. C. Armsden and Mark T. Greenberg. Below is the table showing mean scores and $t$ value of adolescents' on attachment with peer subscale:

\begin{tabular}{|l|l|l|l|}
\hline M & F & t & Level of significance \\
\hline 87.1 & 95.6 & 0.77 & $<.05$ \\
\hline
\end{tabular}

Table 1.3: showing the mean difference and $t$ value of males and females on attachment with peers.

The means score of males and females were found to be 87.1 and 95.6 respectively. The $t$ value obtained was 0.77 . The obtained difference between the means of male and females with respect to their attachment level with peer is "insignificant" at 0.05 Level. This is in contradiction with earlier findings of studies by Cotterell (1992) and O'Koon (1997) who have reported that females have stronger attachment to peers than males. 
2) Risk taking behaviour in Adolescents: It is analyzed under two headings, one is risk behaviour measure which measures indulgence in substance use such as tobacco, alcohol, other substances for e.g. bhang etc. and other is about indulgence in sexual activities. To measure the substance use following aspects were taken into consideration. Below are the tables showing the questions and responses of the respondents about substance use:

2 (a) Substance Use Present: respondents were asked- Have you ever tried alcohol or any other kind of substance?

\begin{tabular}{|l|l|l|}
\hline $\begin{array}{l}\text { Tried alcohol or other } \\
\text { substance }\end{array}$ & \% in FEMALES & $\%$ in MALES \\
\hline & $10 \%$ & $90 \%$ \\
\hline
\end{tabular}

Table 2.1showing the percentage of substance use among males and females.

It is clear from the above table that only $10 \%$ of the females have tried alcohol and other substance while $90 \%$ of the males have tried alcohol and other substances. The prevalence of substance use was higher among males than females, which means males are more indulged in risk taking behaviour than females.

2 (a) (i) Substance Taken: respondents were asked about which substances they have tried.

\begin{tabular}{|l|l|l|}
\hline & Females & Males \\
\hline Tobacco & $10 \%$ & $90 \%$ \\
\hline Alcohol & $10 \%$ & $80 \%$ \\
\hline Other substance/ Drugs & $0 \%$ & $80 \%$ \\
\hline
\end{tabular}

Table 2.2 showing percentage of kind of substance males and females have tried.

It can be seen from the above table that $10 \%$ of the Females have tried cigarette and alcohol and $90 \%$ of Males have tried cigarette and $80 \%$ have taken alcohol and other substance. It may be due to low attachment with parents and peers among males. As, Biglan et al. (2004) in a study showed that when parental monitoring was reported to be inadequate, adolescents were more likely to report associating with deviant peers and more likely to smoke.

2(a) (ii) Age When Tried: subjects were asked about their age they have taken substance first.

\begin{tabular}{|l|c|c|}
\hline \multicolumn{1}{|c|}{ AGE } & \multicolumn{1}{|c|}{ Females } & Males \\
\hline $\mathbf{1 2 - 1 4}$ & 0 & $10 \%$ \\
\hline $\mathbf{1 5}-17$ & 0 & $40 \%$ \\
\hline $\mathbf{1 8 - 2 0}$ & $10 \%$ & $40 \%$ \\
\hline
\end{tabular}

Table 2.3 showing age of males and females when they tried the substance for the first time

Table 2.3 shows that $10 \%$ of Females were between age 18-20 at the time of their first substance use while $10 \%$ of Males have tried between age 12-14, 40\% between age $15-17$ and $40 \%$ between ages 18-20.The substance use was started among boys at a very early age than girls. Gardner and Steinberg (2005) in a study found that risk taking and risky decision making decreased with age; participants took more risks, focused more on the benefits than the costs of risky behaviour, and made riskier decisions when in peer groups than alone; and peer effects on

(C) The International Journal of Indian Psychology, ISSN 2348-5396 (e)| ISSN: 2349-3429 (p) | 65 
risk taking and risky decision making were stronger among adolescents and youths than adults. These findings support the idea that adolescents are more inclined toward risky behaviour and risky decision making than are adults and that peer influence plays an important role in explaining risky behaviour during adolescence.

2(a) (iii) Tried with whom: subjects were asked with whom they have taken substance for the first time.

\begin{tabular}{|l|l|l|}
\hline & \multicolumn{1}{|c|}{ Females } & Males \\
\hline Alone & $0 \%$ & $40 \%$ \\
\hline Friends & $100 \%$ & $40 \%$ \\
\hline Siblings/relatives & $0 \%$ & $10 \%$ \\
\hline
\end{tabular}

Table 2.4: showing responses on- with who did adolescents tried the substance for the first time

The above table show that $100 \%$ of Females has taken with friends and $40 \%$ of Males has taken alone and with friends and $10 \%$ with siblings and relatives. Brown, (2004) Steinberg \& Silverberg (1986)in a study found that although adolescent risk taking often occurs in groups, it is not known whether the greater prevalence of group risk taking observed among adolescents stems from the fact that adolescents spend more time in peer groups or from the heightened levels of susceptibility to peer influence that have been shown to characterize adolescence.

2(a) (iv) Praise from friends: subjects were asked did their peers appreciate them for trying substance and alcohol.

\begin{tabular}{|l|l|l|}
\hline & Yes & No \\
\hline $\mathrm{F}$ & $0 \%$ & $0 \%$ \\
\hline $\mathrm{M}$ & $40 \%$ & $60 \%$ \\
\hline
\end{tabular}

Table 2.5 showing percentage of adolescents who were appreciated for substance use by peers It was found that $0 \%$ of Females was appreciated for trying substance and alcohol while $60 \%$ of Males were appreciated for taking substance and alcohol and 40\% of Males were not. Females reported to have tried substance for the first time with peers, and then also they were not appreciated by their peers for trying it.

2(a) (v) Any Guilt: subjects were asked to tell in yes or no about their feeling of guilt due to indulgence in substance use.

\begin{tabular}{|l|l|l|}
\hline & Females & Males \\
\hline Percentage & $100 \%$ & $30 \%$ \\
\hline
\end{tabular}

Table 2.6 Showing percentage of reported feeling of guilt among males and females.

The above table shows that $100 \%$ of Females reported that they felt guilty because of taking alcohol and cigarette while only 30\% of Males reported feeling of guilt for substance use. 
A Study on Risk Taking Behaviour among Adolescents and Their Attachment with Parents and Peers

2(a) (vi) Was it due to peer pressure: subjects were asked that was indulgence in substance use was due to peer pressure?

\begin{tabular}{|l|l|l|}
\hline & Yes & No \\
\hline Females & $100 \%$ & - \\
\hline Males & $10 \%$ & $90 \%$ \\
\hline
\end{tabular}

Table 2.7 showing percentage of substance use due to peer pressure.

It was found that among females $100 \%$ of substance use was due to peer pressure while only 10 $\%$ of the males reported substance use due to peer pressure. Other reasons among males for substance use were found to be experimentation, trial, etc.

2(b) Substance use not present: next section of the questionnaire was for those who never indulged in any kind of substance use. Following questions were asked to such adolescents:

2(b) (i) Do Peers Make Fun: subjects were asked that do their friends make fun of them because they have not yet tried cigarette or alcohol:

\begin{tabular}{|l|l|l|}
\hline & Yes & No \\
\hline Females & - & - \\
\hline Males & $80 \%$ & $20 \%$ \\
\hline
\end{tabular}

Table 2.8 showing percentage of adolescents who faced taunts because of no indulgence in substance use.

The above table shows that $0 \%$ of Females faced taunts due to no indulgence in substance abuse while in Males $80 \%$ of them faced taunts due to this. Thus it can be inferred from the above finding that one of the factor of male substance use is to maintain their image in front of peers and to escape from being made fun of for not trying such things.

\section{3(A) Sexual Debut:}

3(A) (I) Sexual experience: subjects were asked that did they ever have sexual intercourse (means entering of penis into female vagina).

\begin{tabular}{|l|l|l|}
\hline & Females & Males \\
\hline Percentage & $10 \%$ & $30 \%$ \\
\hline
\end{tabular}

Table 3.1 showing percentage of males and females who had sexual intercourse

The above table shows that only $10 \%$ of Females had reported sexual experience while $30 \%$ of Males reported to have been indulged in sexual activity. Tope (2012) in a study reported that boys tend to be more sexually active than girls, while involvement in sexual activity increased with age.

3(A) (II) At what age: Respondents were asked about their age when they had sexual intercourse for the first time.

\begin{tabular}{|l|l|l|}
\hline & females & males \\
\hline Age & 19 years & 17.5 years \\
\hline
\end{tabular}

Table 3.2 showing age of sexual intercourse for the first time

(C) The International Journal of Indian Psychology, ISSN 2348-5396 (e) | ISSN: 2349-3429 (p) | 67 
The above table shows that Females indulged at age of 19 years while males at an age of 17.5.The onset of sexual behaviour among males was found to be earlier than females. This finding was in contradiction to the findings of Tope (2012) who in a study found that there was no difference in terms of age and sex. The study established that peers exert great influence on the adolescent through various means. These include exposure to pornographic films, pornographic magazines, romantic novels, and discussion of sexual issues.

3(A) (3) Guilt: Respondents were asked whether they were guilty of indulging in sexual activity or not?

\begin{tabular}{|l|l|l|}
\hline & Females & Males \\
\hline Yes & $100 \%$ & $20 \%$ \\
\hline No & - & $10 \%$ \\
\hline
\end{tabular}

Table 3.3 showing reported feeling of guilt among adolescents

$100 \%$ of Females reported to have feeling of guilt while only $20 \%$ of the males reported that they felt guilty for engaging in sexual activity. In contrast to this $10 \%$ of the males said that they were not guilty for having indulged in sexual activity.

3(b) Sexual debuts not present:

3(B) (I) those who have not engaged in sexual activity if get a chance will they engage?

\begin{tabular}{|l|l|l|}
\hline & Females & Males \\
\hline Percentage (out of seventy) & $0 \%$ (yes) & $40 \%$ (yes) \\
\hline & $90 \%$ (no) & $30 \%$ (no) \\
\hline
\end{tabular}

Table 3.3showing responses of adolescents on whether they will engage in sexual activity if they get a chance to or not

The responses shows that $90 \%$ of Females does not want to indulge in sexual activity before marriage while $40 \%$ of Males said if they get a chance, they will indulge while $30 \%$ of males reported that they will not indulge in sexual activity before marriage. Musick (1993), in a study found that teenagers also want to experience adult like life by having sexual activity. Many adolescents view sexual activity as way to develop adult identity. They look for validation from opposite sex. Sexual behaviour also gives way to challenge and confront parents who have opposite stand towards independence.

3(B) (II) Respondents were asked- do your friends make fun of you because you are still virgin?

\begin{tabular}{|l|l|l|}
\hline & Yes & No \\
\hline Females & - & $90 \%$ \\
\hline Males & $40 \%$ & $30 \%$ \\
\hline
\end{tabular}

Table 3.3 showing responses on being ridiculed because of being a virgin

The above table shows that $90 \%$ of the girls and $30 \%$ of the boys did not face any ridicule because they were still virgin whereas among boys $40 \%$ of them faced taunts and ridicules

(C) The International Journal of Indian Psychology, ISSN 2348-5396 (e)| ISSN: 2349-3429 (p) | 68 
because they were still virgin. Maxwell (2006) in a study on a group of 55 young people in one area of England and found that at the timing of first sex they were influenced by pressure from peer, but also from individual partners and from the young person themselves. Thus, young men described being pressured by friends, mainly through the use of ridicule, if they were still virgin.

\section{MAIN FINDINGS}

1) The attachment level of females with their parents was higher in comparison to males. This finding supports the study done by Kenny and Donaldson (1991) who found that women were more attached to their parents and felt that parents had a more significant role in emotional support in their lives. May be this is the reason that females were found to be less engaged in risk taking behaviour than males.

2) The indulgence in substance use was found to be higher in males in comparison to females. It was found that in females the desire of indulging in substance use and sexual activity was low as compared to males. First time indulgence in such behaviour was reported in presence of peers and due to peer pressure. Males reported that they faced ridicule because of not engaging in sexual activities and substance use.

\section{Acknowledgments}

The author appreciates all those who participated in the study and helped to facilitate the research process.

\section{Conflict of Interests}

The author declared no conflict of interests.

\section{REFERENCES}

Armsden, G., and Greenberg, M. (1987).” The inventory of parent and peer attachment. Individual differences and their relationship to psychological well- being in adolescence.”Journal of youth and adolescence, Vol. 16.

Bakker, J. and Denessen, E. (2007).’The concept of parent involvement.”International Journal about Parents in Education, Vol.1.

Crockett J., Raffaelli M., and Moilanen L.,(2003) “Adolescent Sexuality: Behaviour and Meaning.” Faculty Publications, Department of Psychology. Paper 245.

Fischer \& Corcoran," Measures for Clinical Practices and Research."

Gardner M., and Steinberg L., (2005).” Peer Influence on Risk Taking, Risk Preference, and Risky Decision Making in Adolescence and Adulthood: An Experimental Study.” Journal of Developmental Psychology by the American Psychological Association, Vol. 41

Maxwell A., (2002) "Friends: The Role of Peer Influence Across Adolescent Risk Behaviours.” Journal of Youth and Adolescence, Vol. 31, pp. 267-277.

Maxwell C., and Chase E., (2008) "Peer pressure - beyond rhetoric to reality." Journal of Sex Education, Vol. 8, 303-314 
O'Koon, J. (1997) “Attachment to Parents and Peers in Late Adolescence and Their Relationship with Self-Image.” Journal Adolescence, Vol. 32.

Richard M., and Laurence D., "Handbook of Adolescent Psychology: Contextual influences on adolescent development." Volume 2

Sarah W., \&William R., (2006).” Substance use and risk-taking among adolescents.” Journal of Mental Health

How to cite this article: Uzaina, A Srivastava (2016), A Study on Risk Taking Behaviour among Adolescents and Their Attachment with Parents and Peers, International Journal of Indian Psychology, Volume 3, Issue 4, No. 59, ISSN 2348-5396 (e), ISSN: 2349-3429 (p), DIP: 18.01.063/20160304, ISBN: 978-1-365-26307-1 